\title{
INTERNET: PUBLICAÇÕES OFENSIVAS EM REDES SOCIAIS E 0 DIREITO À INDENIZAÇÃO POR DANOS MORAIS
}

\author{
INTERNET: OFFENSIVE PUBLICATIONS IN SOCIAL NETWORKS AND THE \\ RIGHT TO COMPENSATION FOR MORAL DAMAGES
}

TAISE RABElo Dutra TRENTIN

Advogada. Mestre em Direito Público pela Universidade de Santa Cruz do Sul -UNISC, Pós-graduada em direito empresarial pela Pontifícia Universidade Católica do Rio Grande do Sul - PUCRS, Pós-graduanda em Direito e Processo do Trabalho pela Universidade Anhanguera - UNIDERP. Participou como integrante do Grupo de Pesquisas Políticas Públicas no tratamento dos conflitos, coordenado pela Prof. Pós-Dra. Fabiana Marion Spengler, e do Grupo de estudos de Políticas Públicas para a Inovação e a Proteção Jurídica da Tecnologia, coordenado pela Profa. Pós-Dr ${ }^{a}$. Salete Oro Boff, vinculados ao Programa de Pós-Graduação em Direito, Mestrado e Doutorado da UNISC, e certificado pelo CNPQ. Integrante do Grupo de Pesquisa: Direito, Cidadania e Políticas Públicas, coordenado pela Prof ${ }^{a}$. Pós-Dra. Marli Marlene Moraes da Costa, vinculado ao Programa de Pós Graduação em Direito - Mestrado e Doutorado da UNISC.

Endereço eletrônico: taise@dutratrentin.adv.br

SANDRO SEIXAS TRENTIN

Advogado. Mestre em Direito Público pela Universidade de Santa Cruz do Sul -UNISC, Pós-graduada em direito Processual civil e Pós-graduado em Direito Tributário pela Universidade Anhanguera - UNIDERP. Participou como integrante do Grupo de Pesquisas Políticas Públicas no tratamento dos conflitos, coordenado pela Prof. Pós-Dra.

Fabiana Marion Spengler, e do Grupo de estudos de Políticas Públicas para a Inovação e a Proteção Jurídica da Tecnologia, coordenado pela Profa. Pós-Dra ${ }^{a}$. Salete Oro Boff, vinculados ao Programa de Pós-Graduação em Direito, Mestrado e Doutorado da UNISC, e certificado pelo CNPQ. Endereço eletrônico: sandro@dutratrentin.adv.br

\section{RESUMO}

0 presente artigo trata sobre questões relacionadas à internet, as formas de utilização e espécies de provedores, bem como os danos morais por publicações indevidas em redes sociais. Abordar-se-á questão dos direitos da personalidade, como o direito à imagem, direito à honra, direito à privacidade, direito à intimidade na era da internet, tendo em vista os abusos e utilização de imagens ofensivas veiculadas pelos internautas. Além do mais, tem como objetivo analisar quanto à responsabilidade civil daqueles que divulgam mensagens indesejadas, causando sérios danos por comentários publicados na internet, bem como analisando a questão da responsabilização dos provedores de sites de relacionamentos. Ainda, verificar-se-á acerca do entendimento jurisprudencial no Direito Brasileiro. Para a realização desse artigo, utilizou-se o método de abordagem hipotéticodedutivo, método de procedimento monográfico e a técnica de pesquisa bibliográfica.

Palavras-chave: dano moral; direitos de personalidade publicações indevidas; redes sociais; responsabilidade Civil.

\begin{abstract}
This article is about the law and the Internet, uses and types of providers, as well as damages for unauthorized publications on social networks. It will address the issue of personality rights, such as image rights, the right to honor, right to privacy, right to privacy in the Internet age, with a view to abuse and use of offensive images transmitted by the Internet. Moreover, aims to analyze about liability those who disclose unwanted messages, causing serious damage by comments posted on the Internet. Still, there would be about understanding the Brazilian law jurisprudence. To carry out this article, we use the method of hypothetical-deductive approach, method, procedure and technique of monographic literature.
\end{abstract}

Keywords: damage; personality rights; publications undue; social networks; civil responsibility. 


\section{SUMÁRIO}

INTRODUÇAO; 1. INTERNET: UTILIZAÇÃO E ESPÉCIES DE PROVEDORES. 2. DIREITOS DA PERSONALIDADE: AS REDES SOCIAIS VIRTUAIS. 3. OS DANOS MORAIS POR PUBLICAÇÕES INDEVIDAS EM REDES SOCIAIS: ENTENDIMENTO JURISPRUDENCIAL. CONCLUSÃO. REFERÊNCIAS.

\section{INTRODUÇÃO}

O presente artigo tem por objetivo apresentar a ligação entre o direito e a internet, analisando os direitos de personalidade, quando uma pessoa tiver sua imagem exposta de forma abusiva nas redes sociais. Antigamente, a internet não era utilizada por todos, já nos dias atuais é difícil encontrar alguma pessoa que não faça uso habitual deste meio, pois é o meio rápido e prático de se manter contato e se atualizar mundialmente sobre tudo e todos, assim sendo é facilitado à publicação indevida da imagem humana no ambiente virtual.

Com a expansão da internet, as novas tecnologias da informação, surgimento de blogs, redes sociais como Orkut, Facebook, Youtube, blogs, surgem trazendo mudanças ao contexto social contemporâneo. Dessa forma, acentua-se muito a comunicação virtual entre as pessoas, dando a oportunidade à prática de relacionamentos, atividades comerciais. Por outro lado, cresce também a utilização desses meios para prática de ato ilícito, como o desrespeito à intimidade de mensagens indesejadas, publicações indevidas que atingem diretamente à moral, à honra, podendo caracterizar crimes de calúnia, injúria, difamação, entre outros.

Nesse sentido, analisar-se-á quanto à jurisprudência majoritária no Direito Brasileiro, no que tange aos atos ilícitos cometidos no âmbito virtual.

\section{INTERNET: UTILIZAÇÃO E ESPÉCIES DE PROVEDORES}

As redes sociais apresentam-se como espaços de interação entre os sujeitos, em constante movimento, formando e permanecendo os laços. Segundo Duarte e Kraus ${ }^{1}$ conceituam rede social como uma estrutura social composta por pessoas ou organizações, conectadas por um ou vários tipos de relações, que partilham valores e objetivos comuns.

\footnotetext{
${ }^{1}$ Duarte, Fábio e Frei, Klaus. Redes Urbanas. In: Duarte, Fábio; Quandt, Carlos; Souza, Queila. O Tempo Das Redes. São Paulo: Perspectiva, 2008. p. 156.

REDESG / Revista Direitos Emergentes na Sociedade Global - www.ufsm.br/redesg v. 1, n. 1, jan.jun/2012
} 
Acrescenta o mesmo autor que uma das características fundamentais na definição das redes é a sua abertura e porosidade, possibilitando relacionamentos horizontais e não hierárquicos entre os participantes, referindo que as redes não são, portanto, apenas uma outra forma de estrutura, mas quase uma não estrutura, no sentido de que parte de sua força está na habilidade de se fazer e desfazer rapidamente ${ }^{2}$.

Segundo Corrêa:

A Internet é um sistema global de rede de computadores que possibilita a comunicação e a transferência de arquivos de uma máquina a qualquer outra máquina conectada na rede, possibilitando, assim, um intercâmbio de informações sem precedentes na história, de maneira rápida, eficiente e sem a limitação de fronteiras, culminando na criação de novos mecanismos de relacionamento ${ }^{3}$.

É nesse espaço que qualquer um pode publicar e divulgar conteúdos com outros internautas. Dessa forma, menciona Wolton ${ }^{4}$ que cada um pode agir sem intermediário quando bem quiser sem filtro, nem hierarquia e, também pode vir a produzir reflexos na esfera jurídica. Menciona, ainda, que as trocas de informações podem vir a causar danos, podendo ensejar a necessidade de reparação.

Para Cogo e Brignol $^{5}$, no caso de concentração de acesso a um número reduzido de páginas, como a de buscadores Google, Yahoo e MSN, há um movimento parecido com o que ocorre nos grupos corporativos de mídia, com a estruturação de uma lógica assimétrica de "poucos para muitos". No entanto, Fischer ${ }^{6}$ refere que a internet cresce a partir de um "binômio de concentração e multiplicação de suas propriedades comunicacionais".

Com o desenvolvimento das ferramentas tecnológicas, principalmente aquelas promovidas pelo advento da Internet, emergem em nossa sociedade novas formas de relação, comunicação e organização das atividades humanas, entre elas, merecem destaque o estudo de redes sociais virtuais. As redes sociais apoiadas por computadores utilizam-se de diferentes

\footnotetext{
${ }^{2}$ Duarte, Fábio e Frei, Klaus. Redes Urbanas. In: Duarte, Fábio; Quandt, Carlos; Souza, Queila. O Tempo Das Redes. São Paulo: Perspectiva, 2008. p. 156.

${ }^{3}$ CORRÊAA, Gustavo Testa. Aspectos jurídicos da Internet. São Paulo: Saraiva, 2000. p.135.

${ }^{4}$ WOLTON, D. Internet, e depois? Porto Alegre: Sulina, 2003, p.85.

${ }^{5}$ FISCHER, Gustavo Daudt. As trajetórias e características do YouTube e Globo Media Center/ Globo Vídeos: Um olhar comunicacional sobre as lógicas operativas de websites de vídeos para compreender a constituição do caráter midiático da web. 2008. Tese (Doutorado em Ciências da Comunicação) Programa de Pós Graduação em Ciências da Comunicação, Universidade do Vale do Rio dos Sinos, São Leopoldo, RS, 2008, p.39.

${ }^{6}$ COGO, Denise; BRIGNOL, Liliane Dutra. Redes sociais e os estudos da recepção na internet. Disponível em: <http://compos.com.puc-rio.br/media/gt12_denise_cogo.pdf>. Acesso em: 1 jul. 2012.
}

REDESG / Revista Direitos Emergentes na Sociedade Global - www.ufsm.br/redesg v. 1, n. 1, jan.jun/2012 
recursos, entre eles: e-mails, fóruns, listas de discussão, sistemas de boletins eletrônicos, Chats, Softwares Sociais como Orkut, entre outros. A formação de redes de interação vem atingindo as mais diversas esferas e campos de conhecimento, desde o plano econômico, científico, cultural etc. No campo econômico, a exploração do nicho social networking passa a ser alvo de interesse de empresas que estão vendo no ramo das redes sociais virtuais um amplo espaço para negociação de produtos e serviços e, enxergando também, o potencial de relacionamentos estabelecidos nas comunidades como forte capital social da atualidade.

Além disso, a comunicação em rede tem sido explorada como instrumento de ativação de movimentos sociais e culturais como a luta dos direitos humanos, feministas, ambientalistas, etc. Na educação, a participação em comunidades virtuais de debate e argumentação encontra um campo fértil a ser explorado. Através dessa complexidade de funções, percebe-se que as redes sociais virtuais são canais de grande fluxo na circulação de informação, vínculos, valores e discursos sociais, que vem ampliando, delimitando e mesclando territórios. Entre desconfiados e entusiásticos, o fato é que as redes sociais virtuais são convites para se repensar as relações em tempo pós-modernos ${ }^{7}$

Vivendo em pleno século XXI, cada dia que passa a internet tem se tornado o meio de comunicação mais usado intensamente no mundo inteiro, com este uso frequentemente por seus navegadores, surgem diversas redes sociais como: Google, Youtube, Facebook, Orkut, Twitter, Linkedin..., onde cada um tem o livre acesso de publicação de sua vida, seus preceitos, seus gostos, suas ideias, suas políticas, bem como adicionar pessoas, postar fotos, links, jogos, enfim uma infinidade de opções que é proporcionado na bendita ou maldita rede social. Refere-se que é bendita, porque é a forma rápida e prática de contatar com o mundo afora, seja qual for o motivo; e maldita, porque muitos têm usado tais redes para denegrir a imagem humana, postando fotos íntimas nesses sites públicos, atacando com ofensas morais, o que tem gerado vários casos na justiça.

Nesse aspecto, verifica-se que o uso do e-mail, a interatividade nos sites e a possibilidade de criar espaços virtuais exibindo, postando ideias e fatos em blogs, entre outras coisas, mudou a forma de dialogar entre as pessoas, que têm o acesso à internet nas suas residências, no trabalho e até mesmo em lan house. "O exame de seus aspectos técnicos e sua

\footnotetext{
${ }^{7}$ MACHADO, Joicemegue Ribeiro; TIJIBOY, Ana Vilma. Redes Sociais Virtuais: um espaço para efetivação da aprendizagem cooperativa. Disponível em: <http://www.inf.ufes.br/ crnascimento/artigos/ a37_redessociaisvirtuais.pdf >. Acesso em: 20 jul.2012.

REDESG / Revista Direitos Emergentes na Sociedade Global - www.ufsm.br/redesg v. 1, n. 1, jan.jun/2012
} 
repercussão no modo de vida apontam para uma transformação cultural de hábitos e comportamentos de grandes proporções"».

Desse modo, cumpre salientar o reconhecimento do dano moral e de sua reparabilidade pelo Código de 2002 e pela Constituição Brasileira de 1988 que definiu expressamente em seu artigo $5^{\circ}$, incisos $\mathrm{V}$ e $\mathrm{X}$ :

Art $5^{\circ}$. Todos são iguais perante a lei, sem distinção de qualquer natureza, garantindo-se aos brasileiros e aos estrangeiros residentes no País a inviolabilidade do direito à vida, à liberdade, à igualdade, à segurança e à propriedade, nos termos seguintes:

V - é assegurado o direito de resposta, proporcional ao agravo, além da indenização por dano material, moral ou à imagem;

$X$ - são invioláveis a intimidade, a vida privada, a honra e a imagem das pessoas, assegurado o direito a indenização pelo dano material ou moral decorrente de sua violação;

O Novo Código Civil Brasileiro, ratificando posição já há muito sedimentada em nossa doutrina e jurisprudência, previu em seu artigo 186: “Aquele que, por ação ou omissão voluntária, negligência ou imprudência, violar direito e causar dano a outrem, ainda que exclusivamente moral, comete ato ilícito."

Portanto, os sites permitem a livre manifestação dos usuários, de modo que estes podem publicar o que quiserem, podendo gerar informações ilícitas, abusivas, violação de direitos autorais e atitudes lesivas a direitos personalíssimos de outrem.

\section{DIREITOS DA PERSONALIDADE: AS REDES SOCIAIS VIRTUAIS}

Inicialmente, os direitos de personalidade são aqueles direitos relativos à dignidade da pessoa humana. Nesse sentido, Scapim ${ }^{9}$ refere que os direitos da personalidade são subjetivos, ou seja, oponíveis erga omnes, os quais se aplicam a todos os homens. Acrescenta-se que são aqueles direitos que a pessoa tem para defender o que é seu, como: a vida, a integridade, a liberdade, a sociabilidade, a honra, a privacidade, a autoria, a imagem, entre outros.

\footnotetext{
${ }^{8}$ MIRAGEM, Bruno. Responsabilidade por danos na sociedade de informação e proteção do consumidor: desafios atuais da regulação jurídica da Internet. Revista de Direito do Consumidor: RDC, Sao Paulo, ano 18, n. 70 , p. 49, abr.-jun. 2009, p.43.

${ }^{9}$ SCAPIM, Eric. Direitos da personalidade: direito à imagem. Disponível em: <

<http://www.viannajr.edu.br/site/menu/publicacoes/publicacao_direito/pdf/edicao2/Art02200511.pdf> Acesso em: 1 jul.2012.
}

REDESG / Revista Direitos Emergentes na Sociedade Global - www.ufsm.br/redesg v. 1, n. 1, jan.jun/2012 
Venosa ${ }^{10}$ explica que os danos decorrentes da violação desses direitos possuem caráter moral; que os danos patrimoniais que eventualmente podem decorrer são de nível secundário, mas é no campo dos danos morais que se situa a transgressão dos direitos da personalidade.

Em relação ao direito à honra, prevista no art. $5^{\circ}$, inciso $X$ da Constituição Federal $/ 88^{11}$. É proveniente do latim honor, indica a própria dignidade de uma pessoa, que vive com honestidade e probidade, pautando seu modo de vida nos ditames da moral, refletindo como honra objetiva ou honra subjetiva. Verifica-se também que a pessoa jurídica também pode ser objeto de ofensa ao direito à honra, pois poderá ter sua reputação maculada, ainda que esta não possua o sentimento da própria dignidade ${ }^{12}$.

Quanto ao direito à imagem, este também é considerado um direito da personalidade, extrapatrimonial de caráter personalíssimo, protegendo os interesses dos indivíduos de oporemse a publicação de sua imagem quando julgarem ser desnecessário e invasivo, sendo previsto no novo Código Civil e na Constituição federal em seu art. $5^{\circ} \mathrm{V}, \mathrm{X}, \mathrm{XXVIII.}$

O direito à imagem vincula-se a tudo que é forma estética, ou seja, o corpo, o rosto, perfil da pessoa. Devido a isso, nos casos de abuso não autorizado da imagem de uma pessoa, esta pode requerer perante a justiça, a restituição do dano através de indenização ${ }^{13}$. Nesse contexto, o Superior Tribunal de Justiça editou a Súmula 403 que refere: “Independe de prova do prejuízo a indenização pela publicação não autorizada da imagem de pessoa com fins econômicos ou comerciais". ${ }^{14}$

Segundo Braga e Rover ${ }^{15}$, o ambiente virtual é propício para condutas odiosas que reclamam energética atitude do Poder Público ou de quem the faça às vezes, como citou o exemplo ocorrido com a modelo Daniela Cicarelli, quando um cinegrafista amador a flagrou em momentos de intimidade com seu namorado em uma praia europeia, sendo esta cena filmada

\footnotetext{
${ }^{10}$ VENOSA, Silvio de Salvo. Direito Civil: Parte geral. 5.ed. São Paulo: Atlas, 2005. p.198.

${ }^{11} \mathrm{Art} .5^{\circ}$ da Constituição Federal 1988, inciso X: "são invioláveis a intimidade, a vida privada, a honra e a imagem das pessoas, assegurado o direito a indenização pelo dano material ou moral decorrente de sua violação".

12 MARQUES, Andréa Neves Gonzaga Marques Disponível em: <http://direito-legal.jusbrasil.com.br/ noticias/2166798/direito-a-honra>. Acesso em: 1 jul. 2012.

${ }^{13}$ SCAPIM, Eric. Direitos da personalidade: direito à imagem. Disponível em: http://www.viannajr.edu.br/site/menu/publicacoes/publicacao_direito/pdf/edicao2/Art02200511.pdf Acesso em: 1 jul.2012.

14 Disponível em: <http://www.stj.gov.br/portal_stj/publicação/engrine.wsp?tmp.area=682\&tmp. texto=94439>. Acesso em: 3 jul.2012.

${ }^{15}$ BRAGA, Diogo de Melo; BRAGA, Marcus de Melo; ROVER, Aires José. Responsabilidade Civil das Redes Sociais no Direito Brasileiro. Disponível em: http://www.egov.ufsc.br/portal/sites/default/ files/aires_braga.pdf. Acesso em: 30 jun.2012.

REDESG / Revista Direitos Emergentes na Sociedade Global - www.ufsm.br/redesg v. 1, n. 1, jan.jun/2012
} 
através de um celular que rapidamente as imagens foram publicadas e espalhadas na rede, dispersando-se pela internet de forma exponencial, impossibilitando qualquer tentativa de controlar o uso danoso da imagem.

Também fato recentemente ocorrido foi com a atriz e modelo Carolina Dickmann, a qual teve suas fotos íntimas publicadas nas redes sociais, ferindo a sua intimidade. Essa conduta é uma forma de denegrir a imagem de alguém.

Acrescenta-se ainda, o direito à privacidade, constitucionalmente protegido, as circunstâncias que um indivíduo compartilha com outras pessoas, mais intensamente ou não, ao passo que aquela trata dos aspectos internos, inerentes de cada pessoa, como religião, orientação sexual, orientação política ${ }^{16}$.

Para Bastos, o direito à privacidade é "a faculdade que tem cada indivíduo de obstar a intromissão de estranhos em sua vida privada e familiar, assim como de impedir-lhes o acesso a informações sobre a privacidade de cada um, e também impedir que sejam divulgadas informações sobre esta área da manifestação existencial do ser humano" ${ }^{17}$.

Ferraz Júnior ${ }^{18}$ menciona que a privacidade é um direito cujo titular, o sujeito, nos termos do art. $5^{\circ}$, caput, da $\mathrm{CF} / 88$, é toda e qualquer pessoa física ou jurídica, brasileira ou estrangeira, residente ou transeunte no país. Desse modo, todos os sujeitos envolvidos nas relações jurídicas criadas pelo uso da Internet têm a seu favor a garantia da privacidade, quer os internautas/usuários, quer os provedores de acesso ou serviços. Refere, ainda, que a privacidade tem por conteúdo a faculdade de o sujeito nas suas relações sociais exigir dos outros o respeito e resistir e não permitir a violação do que the é próprio. 0 objeto é toda a integridade moral do sujeito, composta pelo nome, imagem, reputação, intimidade, entre outros.

Nesse sentido, o direito à privacidade, direito fundamental garantido em nosso texto constitucional, pode ser o mais atingido quando se trata de relações contratuais por meio da web. Esse desrespeito a uma das categorias de Direitos Humanos decorre do fato de ser necessário o fornecimento de diversas informações de caráter pessoal para estabelecer um

\footnotetext{
${ }^{16}$ BRAGA, Diogo de Melo; BRAGA, Marcus de Melo; ROVER, Aires José. Responsabilidade Civil das Redes Sociais no Direito Brasileiro. Disponível em: <http://www.egov.ufsc.br/portal/sites/default/files/ aires_braga.pdf>. Acesso em: 30 jun.2012.

${ }^{17}$ BASTOS, Celso Ribeiro. Curso de direito constitucional. 21 .ed. São Paulo: Saraiva, 2000.

18 FERRAZ JÚNIOR, Tercio Sampaio. Sigilo de dados: o Direito à privacidade e os limites à função fiscalizadora do Estado. 2006. Disponível em <http://www.terciosampaioferrazjr.com.br/?q=/publicacoescientificas/49> Acesso em: 5 ago.2012.
}

REDESG / Revista Direitos Emergentes na Sociedade Global - www.ufsm.br/redesg v. 1, n. 1, jan.jun/2012 
vínculo contratual, pois a web ainda não é totalmente segura no que tange a proteção de dados $^{19}$.

No ambiente virtual, as questões relativas à privacidade do internauta em meio à era virtual é algo que deve ser delicadamente tratado, posto que, dada a inexistência de um direito amplo e eficaz para tratar da questão, conflitos existentes tendem a aumentar face ao crescimento do número de adeptos à rede, bem como da infinidade de informações que circulam frequentemente no espaço virtual, expondo a privacidade do indivíduo proporcionando a violação de tal preceito constitucional em questão ${ }^{20}$.

Ainda, refere o mesmo autor, que as leis devem acompanhar as mudanças da sociedade, de forma a reparar qualquer tipo de problema que possa existir. Sem leis não existe direito, e impunes, os infratores da norma abusam das oportunidades para satisfazerem suas necessidades, sejam elas quais forem ${ }^{21}$.

\section{OS DANOS MORAIS POR PUBLICAÇÕES INDEVIDAS EM REDES SOCIAIS: ENTENDIMENTO JURISPRUDENCIAL}

Com o advento da internet, as pessoas têm cada vez mais a oportunidade de expressar sua opinião através do ciberespaço, mas ao mesmo tempo em que se tem essa liberdade de se dizer o que se quer, também surge a necessidade de responsabilização pelo que se diz, segundo Zago $^{22}$.

Conforme se verificam nas decisões dos Tribunais no que se refere à responsabilização das redes sociais e dos sites de relacionamentos por danos causados por seus usuários independem de culpa, aplicando o art.927, parágrafo único do Código Civil ${ }^{23}$.

Nesse sentido, alguns entendimentos jurisprudenciais:

\footnotetext{
${ }^{19}$ MARTINS, Flávio Alves. Utilização indevida de informações prestadas nas relações comerciais por meio da internet. Disponível no site: http://sisnet.aduaneiras.com.br/lex/doutrinas/arquivos/051007.pdf. Acesso 20 ago. 2012.

${ }^{20}$ LEITE, Marco Aurélio Souza. Internet e proteção legal à privacidade. Disponível em: http://www.webartigos.com/artigos/direito-de-privacidade-e-internet/18959/\#ixzz1zwbuUPJF. Acesso em 05 julho de 2012.

${ }^{21}$ Ibidem.

22 ZAGO, Gabriela da Silva. A possibilidade de responsabilização civil de terceiros por comentários a internet. Disponível em: <http://www.usp.br/anagrama/Zago_responsabilizacaocivil.pdf>Acesso em: 3 jul.2012.

${ }_{23}$ BRASIL. Código Civil Brasileiro. Disponível em: <http://www.planalto.gov.br/ccivil_03/leis/2002/ 110406.htm> Acesso em: 3 jul.2012.

REDESG / Revista Direitos Emergentes na Sociedade Global - www.ufsm.br/redesg v. 1, n. 1, jan.jun/2012
} 
Decisão. Publicação de comentários vexatórios no Orkut enseja danos morais. A $10^{\mathrm{a}}$ câmara Cível do TJ/MG condenou uma mulher a indenizar em R\$ 3.270,00 por danos morais a ex de seu marido, contra quem fez declarações ofensivas na rede social Orkut. De acordo com a vítima, a mulher agrediu-a verbalmente na porta da loja da qual ela era funcionária. Em seguida, passou a atacá-la fisicamente, com chutes, socos, tapas e puxões de cabelo. A agredida declarou que se sentiu profundamente humilhada, porque foi exposta em local público, numa cidade pequena, próximo ao seu posto de trabalho e em horário de grande movimentação. A funcionária acrescentou ainda que o incidente resultou na sua posterior demissão e em dificuldades financeiras causadas pela perda do emprego. 0 que motivou o ajuizamento da ação, entretanto, foram os comentários que a mulher teria feito em sua página pessoal no Orkut, zombando da aparência da vítima após o incidente e de suas dívidas. A agressora negou ser a autora do perfil, sustentando que a briga envolveu agressões mútuas e que só se defendeu dos golpes recebidos. Para o desembargador Gutemberg da Mota e Silva, relator do recurso, a autora dos comentários não comprovou ter agido em legítima defesa, e as testemunhas confirmaram que o perfil com as ofensas pertencia a ela. "É inegável que a pessoa que é agredida na rua e se torna alvo de comentários negativos sobre sua vida em rede social sofre constrangimentos que afetam sua honra e dignidade", afirmou. Processo relacionado: 0033970829.2010.8.13.0015.

Nesse aspecto, a pessoa sofreu constrangimentos que abalaram sua reputação, de forma que houve, inclusive, agressões, resultando na perda do empregado.

Ademais, existem outros casos que atingem a imagem do individuo, como podemos citar aqueles que divulgam fotografias nas redes virtuais:

AGRAVO INTERNO. DECISÃO MONOCRÁTICA QUE NEGOU SEGUIMENTO À APELAÇÃO. Não desmerecida pelas razões deduzidas no agravo interno, subsiste a decisão que negou seguimento à apelação em conformidade com o art. 557, caput, do Código de Processo Civil. APELAÇÃ̃o CívEL. RESPONSABILIDADE CIVIL. AÇÃO DE INDENIZAÇÃO POR DANOS MORAIS. CRIAÇÃO DE COMUNIDADE COM CONTEÚDO OFENSIVO EM SITE DE RELACIONAMENTOS (ORKUT), UTILIZANDO FOTOGRAFIA DA AUTORA. LEGITIMIDADE PASSIVA. A requerida, na condição de mantenedora do site de relacionamentos em que houve a publicação de imagem da autora, é parte legítima para responder à ação de reparação de danos que tem por fundamento a não retirada do conteúdo ofensivo, mesmo depois a denúncia realizada pelo usuário Preliminar rejeitada. NOTIFICAÇÃO EXTRAJUDICIAL NÃO ATENDIDA PELA RÉ. DEVER DE INDENIZAR. OCORRÊNCIA. Verificada nos autos a desídia da ré, ao não atender a notificação extrajudicial enviada pela autora, por meio da ferramenta de denúncia existente no próprio site, no intuito de ver removida fotografia pessoal utilizada em comunidade de conteúdo ofensivo, causando-lhe abalo à honra e à reputação, resta evidente o 
dever de indenizar. Precedentes desta Corte. Condenação mantida. QUANTUM INDENIZATÓRIO. MANUTENÇÃO. Na fixação da reparação por dano extrapatrimonial, incumbe ao julgador, atentando, sobretudo, para as condições do ofensor, do ofendido e do bem jurídico lesado, e aos princípios da proporcionalidade e razoabilidade, arbitrar quantum que se preste à suficiente recomposição dos prejuízos, sem importar, contudo, enriquecimento sem causa da vítima. A análise de tais critérios, aliada às demais particularidades do caso concreto, conduz à manutenção do montante indenizatório fixado em RS $6.000,00$ (seis mil reais), corrigido monetariamente e acrescido de juros moratórios conforme determinado no ato sentencial. AGRAVO INTERNO DESPROVIDO. (Agravo No 70048719843, Décima Câmara Cível, Tribunal de Justiça do RS, Relator: Paulo Roberto Lessa Franz, Julgado em 31/05/2012).

APELAÇÃO CÍVEL. RESPONSABILIDADE CIVIL. COLISÃO DE DIREITOS FUNDAMENTAIS. DIREITO À INFORMAÇÃO CONTRAPOSTO AO DIREITO À INVIOLABILIDADE DA VIDA PRIVADA, DA HONRA E DA IMAGEM. PROPORCIONALIDADE. OFENSAS PESSOAIS. USO INDEVIDO DE IMAGEM. DEVER DE INDENIZAR. CONFIGURAÇÃO. MAJORAÇÃO DO QUANTUM FIXADO. O presente caso contrapõe o direito de informação de fatos, dados e acontecimentos, os quais devem ser objetivamente apurados, vinculados à veracidade e à imparcialidade ao direito de inviolabilidade da intimidade da vida privada, da honra e da imagem, todos constitucionalmente assegurados. Trata-se, pois, de colisão de direitos fundamentais, cuja solução não impõe o afastamento integral de um ou de outro, mas sim a adequação proporcional de ambos, com eventuais preponderâncias. 0 direito à informação, neste caso concreto, sucumbiu diante da publicação de fato inverídico e inobservância do dever de imparcialidade, ocorrendo abusos. Texto publicado em blog Nova Corja que traz ofensas específicas à pessoa da autora, na época gerente de empresa de telefonia, além do uso indevido, sem autorização, da imagem da autora. Dano moral configurado in re ipsa. Quantum indenizatório majorado. APELO DA AUTORA PROVIDO EM PARTE. APELO DO RÉU DESPROVIDO. UNÂNIME. (Apelação Cível Nº 70042708560, Nona Câmara Cível, Tribunal de Justiça do RS, Relator: Iris Helena Medeiros Nogueira, Julgado em 08/06/2011)

Existem vários outros casos por publicações ofensivas nas redes sociais, como por exemplo:

Danos morais. A ex-empregada, ora recorrente, criou no Orkut a página "Senzala Zest", em cuja descrição se apresenta destinada a"todos aqueles que são ou já foram escravos do Restaurante Zest"(fl. 24). É incontroverso que a ex-empregada criou a página, como também que por ali foram manifestadas várias agressões, como a condição de trabalho escravo (já presente no nome da página), como também à suposta homossexualidade do filho do sócio, ou ainda a desqualificação profissional responsável para the atribuir a condição de "cozinheira de sopão". A criação da chamada "comunidade" produtora de fatos lesivos já é, em si mesma, ato lesivo à honra. Presentes os requisitos que

REDESG / Revista Direitos Emergentes na Sociedade Global - www.ufsm.br/redesg v. 1, n. 1, jan.jun/2012 
justificam o dever de indenizar (artigos 186 e 187 do Código Civil). 0 empregado, criador e moderador de comunidade em sítio de relacionamento (Orkut), que permite a veiculação de conteúdo com potencial ofensivo contra o empregador, está sujeito a responsabilidade civil." (TRT02, Rel. Rafael e. Pugliese Ribeiro, Processo $n^{\circ}:$ 00266-2007-022-02-00-3, julgado em 30/03/2010).

APELAÇÃO CÍVEL - INDENIZAÇÃO POR DANOS MORAIS - AGRESSÃO FÍ́ICA COMENTÁRIOS OFENSIVOS NO ORKUT - DANO MORAL CARACTERIZADO - VALOR DA INDENIZAÇÃO - EXTENSÃO DO DANO - PROPORCIONALIDADE E RAZOABILIDADE. A agressão física, bem como a publicação de comentários ofensivos em página de relacionamento na internet, enseja indenização por danos morais, pois causa sofrimento íntimo, profundo, que fere a dignidade da pessoa ofendida. A indenização deve ser suficiente exclusivamente para reparar o dano, pois se mede pela extensão do dano, nos termos do art. 944, caput, do Código Civil, não podendo ensejar enriquecimento indevido do ofendido. Recurso principal não provido. Recurso adesivo provido em parte. APELAÇÃO CíVEL $\mathrm{N}^{\circ}$ 1.0015.10.003970-8/001 - COMARCA DE ALÉM PARAÍBA - APELANTE(S): J.M.C. APTE(S) ADESIV: L.S.F., - APELADO(A)(S): J.M.C., L.S.F.

Pode se citar outras situações, que expõem os usuários, como por exemplo, a decisão do Tribunal de Justiça de São Paulo, a qual reconheceu a responsabilidade do blogueiro em remover comentários ofensivos de terceiros. No voto, o relator referiu que houve comentários anônimos, o que é incompatível com o disposto no $a r t .5^{\circ}$ da Constituição Federal. Ademais, mencionou que “o direito de expressão é assegurado, porém, vedado o anonimato. Tal dispositivo tem por escopo justamente permitir a identificação de quem expressa sua opinião, para que este possa ser responsabilizado por eventuais abusos"24.

Ademais, o Superior Tribunal de Justiça entendeu que os provedores devem retirar conteúdo ofensivo em 24 horas, sob pena de responder solidariamente com o autor direto do dano. A decisão foi tomada no julgamento de recurso especial interposto pelo Google. Consta no processo que, após ter sido notificado, por meio da ferramenta "denúncia de abusos" (disponibilizada pelo próprio provedor aos usuários do Orkut), da existência de um perfil falso que vinha denegrindo a imagem de uma mulher, o Google demorou mais de dois meses para excluir a página do site. Dessa maneira, o juiz de primeira instância condenou o provedor ao pagamento de indenização por danos morais no valor de R\$ 20 mil. Em apelação, apenas foi

\footnotetext{
${ }^{24}$ BRASIL. Tribunal de Justiça de São Paulo. Agravo de Instrumento n.583.663-4/2-00, $3^{\text {a }}$ Câmara de Direito Privado, Tribunal de Justiça de São Paulo. Rel. Egídio Giacoia. Julgado em 12 de agosto de 2008.

REDESG / Revista Direitos Emergentes na Sociedade Global - www.ufsm.br/redesg v. 1, n. 1, jan.jun/2012
} 
reduzido o valor da indenização para $\mathrm{R} \$ 10$ mil. No recurso especial direcionado ao STJ, o provedor alegou violação ao artigo 186 do Código Civil ${ }^{25}$.

Ainda, ao analisar o pedido, a ministra Nancy Andrighi, relatora do recurso especial, considerou o interesse coletivo envolvido na questão, referindo que a velocidade com que os dados circulam no meio virtual torna indispensável que medidas tendentes a coibir informações depreciativas e aviltantes sejam adotadas célere e enfaticamente, de modo que as mensagens sejam excluídas rapidamente, para minimizar a disseminação do insulto e, consequentemente, os efeitos posteriores à veiculação ${ }^{26}$. Ressalta ainda, o lado da proteção da dignidade e da honra dos que navegam na rede.

Portanto, o provedor de acesso não será responsabilizado pelo conteúdo das informações transmitidas, respondendo apenas se alterar a informação, não cumprir as condições facilitadoras do acesso, não respeitar as normas relativas à atualização da informação, interferir na utilização da tecnologia com o fim de obter dados sobre a utilização da informação ou não retirar a informação armazenada, se houver determinação judicial ou de autoridade administrativa ${ }^{27}$.

A relação que se estabelece entre o provedor de acesso e o usuário consubstancia-se em um contrato de prestação de serviços. O encargo do usuário é de se responsabilizar pelo conteúdo de suas mensagens. Por seu turno, o papel do provedor de acesso é de oferecer serviços de conexão à rede. Essa relação deve ser regulada pelo Código de Defesa do Consumidor, figurando, no polo do consumidor, o usuário, e, no polo do fornecedor, o provedor $^{28}$.

As decisões adequam ao sistema atual as situações de violação de direitos da personalidade por divulgação de ofensas na rede. Como em outras situações de vigilância em massa, não pode o vigilante ser penalizado por tudo que ocorrer, mas apenas quando deixar de tomar providência essencial e específica, sendo responsabilizado por deixar de agir nas situações

\footnotetext{
${ }^{25}$ Disponível no site: http://stj.jusbrasil.com.br/noticias/3160349/terceira-turma-fixa-prazo-de-24-horaspara-retirada-de-pagina-com-conteudo-ofensivo-da-internet. Acesso em 05 julho de 2012.

${ }^{26}$ Nancy Andrighi citou precedente de sua relatoria sobre o tema: "Se, por um lado, há notória impossibilidade prática de controle, pelo provedor de conteúdo, de toda a informação que transita em seu site; por outro lado, deve ele, ciente da existência de publicação de texto ilícito, removê-lo sem delongas" (REsp 1.186.616).

27 VASCONCELOS, Fernando Antonio. Internet: Responsabilidade do provedor pelos danos praticados.Curitiba: Juruá, 2006. p.201.

${ }^{28}$ BARROS, Janine Maria Freitas; BAÚ, Marilise Kostenalki. Dano moral no site de relacionamento pessoal Orkut. Disponível em: http://www.pucrs.br/direito/graduacao/tc/tccll/trabalhos2007_1/ janine_barros.pdf. Acesso em: 5 jul. 2012.

REDESG / Revista Direitos Emergentes na Sociedade Global - www.ufsm.br/redesg v. 1, n. 1, jan.jun/2012
} 
em que deveria e tinha conhecimento. ${ }^{29}$ As recentes decisões do Superior Tribunal de Justiça regulam a responsabilidade dos provedores, reconhecendo-a, sempre que houver negligência na exclusão de informações ofensivas ou impróprias, ainda que tenha afastado a responsabilidade objetiva, preconizada pelo art. 927, par. ún. do Código Civil. Cria-se um novo paradigma para tais casos em que se reconhece a ausência de obrigação geral de vigilância, mas a obrigação de fazer, a partir do momento em que há ciência da violação ou abuso de direitos. 0 entendimento privilegia a eticidade do sistema, a preservação da boa-fé e tutela da confiança ${ }^{30}$.

Nigri entende que:

Se o provedor oferece os serviços de hospedagem de páginas e, porventura, alguma página por ele hospedada veicular conteúdo indevido, ele deverá ser oficialmente notificado para retirar a página do ar, sob pena de não o fazendo, ser co-autor do eventual crime. Caso o provedor esteja colaborando na elaboração de uma página de conteúdo ilegal (pedofilia, racismo, etc.); desde que se comprove sua participação, ele poderá ser responsabilizado ${ }^{31}$.

Cabe referir que, é fundamental o papel do Estado brasileiro, o qual será observado através de casos em que Poder Judiciário interveio com seus julgamentos e que, desse modo, vem elaborando hermeneuticamente soluções para enfrentar o problema da falta responsabilização, ou melhor, da impunidade dos usuários que comente ilícitos penais e civis anonimamente. Também o Poder Legislativo está no âmbito das suas atribuições buscando tratar do tema, e para tanto vem discutindo Projetos de Leis a imposição a todos os envolvidos no uso da Internet de obrigações que combatam a anonimia virtual ${ }^{32}$.

Moraes menciona, ainda, quanto à abordagem da atuação do Ministério Público Federal, pois, extrajudicialmente esta instituição constitucional buscou soluções para os imbróglios ocorridos no serviço Orkut oferecido pela empresa Google. A intenção foi combater as práticas ilícitas que vinham sendo perpetradas com o uso dessa rede de relacionamentos e que eram

\footnotetext{
${ }^{29}$ NETO, Antonio Rulli; AZEVEDO, Renato A. Responsabilidade civil de provedores da internet: novos paradigmas. Disponível em: <http://por-leitores.jusbrasil.com.br/noticias/3161392/responsabilidadecivil-de-provedores-da-internet-novos-paradigmas > Acesso em 31 ago.2012.

${ }^{30}$ Ibidem.

31 NIGRI, Deborah Fisch. Doutrina Jurídica brasileira: Crimes e Segurança na Internet. Caixias do Sul: Plenum, 2001.

32 MORAES. Paulo Francisco Cardoso de. A vedação constitucional do anonimato aplicada à internet. 0 papel do estado brasileiro nna identificação dos usuários e responsabilização dos provedores. Disponível em : <http://www.ambito-juridico.com.br/site/index.php?n_link=revista_artigos_leitura\& artigo_id=9964\&revista_caderno=17>. Acesso em: 31 ago.2012.
}

REDESG / Revista Direitos Emergentes na Sociedade Global - www.ufsm.br/redesg v. 1, n. 1, jan.jun/2012 
agravadas pela falta de identificação dos agentes criminosos, ou seja, tratou-se da conivência do Orkut para com a prática do anonimato no seu serviço ${ }^{33}$.

É necessária a atuação do Estado para combater esses crimes virtuais, não deixando que pessoas fiquem expostas de forma indevida, através de usuários que publicam mensagens ofensivas com intuito de denegrir a imagem e a honra de outrem.

É importante que o nosso ordenamento jurídico tenha mais regulamentos capazes de proteger a privacidade, intimidade, a vida privada e dados pessoais de todos os cidadãos do país, principalmente no que tange a movimentação de dados eletrônicos, pois é um setor que carece de regulamentação. Neste sentido, seria possível a sustentação dos direitos fundamentais de cada indivíduo e a conscientização da sua indispensabilidade e seu valor ${ }^{34}$.

\section{CONCLUSÃO}

Do estudo realizado, depreende-se que as redes sociais passam a ser um lugar para troca de informações, grupos de discussão e de participação democrática. 0 ambiente virtual quando mal utilizado, torna-se propício à prática de diversos ilícitos.

É nesse contexto que se pode constatar que os usuários podem utilizá-la de várias formas, tanto para atividades comerciais, sites de relacionamentos, como de forma ilícita, publicando ofensas a outros internautas, violando os direitos de personalidade, denegrindo sua imagem.

Dessa forma, observa-se que diante a esses abusos na internet, aquele usuário responsável por dizer, publicar, compartilhar mensagens indevidas, deverá ser responsabilizado pelos danos causados. Percebem-se vários casos que envolvem as redes sociais virtuais, é no sentido de criação de perfis falsos, veiculação de informações e imagens ofensivas. Em decorrência disso, pretende-se em diversas demandas, a retirada de perfis e fotografias nos sites, com direito a indenização por danos morais.

\footnotetext{
33 MORAES. Paulo Francisco Cardoso de. A vedação constitucional do anonimato aplicada à internet. 0 papel do estado brasileiro nna identificação dos usuários e responsabilização dos provedores. Disponível no site: http://www.ambito-juridico.com.br/site/index.php?n_link=revista_artigos_leitura\&tartigo_id= 9964\&revista_caderno=17. Acesso em: 31 ago.2012.

${ }^{34}$ MEIRA, Laís Moreschi; SOARES, Matheus Fernandes de Souza; PIRES, Panmella Rodrigues. Direito à privacidade $e$ as relações na internet. Disponível em: http://www.jurisway.org.br/v2/ dhall.asp?id_dh=7319. Acesso em: 31 ago.2012.
}

REDESG / Revista Direitos Emergentes na Sociedade Global - www.ufsm.br/redesg v. 1, n. 1, jan.jun/2012 
No que tange a responsabilidade do usuário infrator, pode se observar, diante dos casos apresentados, que este sofrerá a responsabilização pelas informações ilícitas vinculadas no ambiente virtual, e o provedor do site de relacionamento será responsabilizado somente se deixar de excluir ou bloquear as imagens ou informações ofensivas, após transcorrido certo prazo desde a notificação feita pela vítima.

\section{REFERÊNCIAS}

BARROS, Janine Maria Freitas; BAÚ, Marilise Kostenalki. Dano moral no site de relacionamento pessoal Orkut. Disponível em:

<http://www.pucrs.br/direito/graduacao/tc/tccll/trabalhos2007_1/janine_barros.pdf >. Acesso em: 5 jul. 2012.

BASTOS, Celso Ribeiro. Curso de direito constitucional. 21 .ed. São Paulo: Saraiva, 2000.

BRAGA, Diogo de Melo; BRAGA, Marcus de Melo; ROVER, Aires José. Responsabilidade Civil das Redes Sociais no Direito Brasileiro. Disponível em:

<http://www.egov.ufsc.br/portal/sites/default/files/aires_braga.pdf>. Acesso em: 30 jun.2012.

BRASIL. Código Civil Brasileiro. Disponível em:

<http://www.planalto.gov.br/ccivil_03/leis/2002//10406.htm> Acesso em: 3 jul.2012.

BRASIL. Tribunal de Justiça de São Paulo. Agravo de Instrumento n.583.663-4/2-00, $3^{\text {a }}$ Câmara de Direito Privado, Tribunal de Justiça de São Paulo. Rel. Egídio Giacoia. Julgado em 12 de agosto de 2008.

COGO, Denise; BRIGNOL, Liliane Dutra. Redes sociais e os estudos da recepção na internet. Disponível em: <http://compos.com.puc-rio.br/media/gt12_denise_cogo.pdf >. Acesso em: 1 jul. 2012.

CORRÊA, Gustavo Testa. Aspectos jurídicos da Internet. São Paulo: Saraiva, 2000.

DUARTE, Fábio; FREI, Klaus. Redes Urbanas. In: Duarte, Fábio; Quandt, Carlos; Souza, Queila. O Tempo Das Redes. São Paulo: Perspectiva, 2008.

FERRAZ JÚNIOR, Tercio Sampaio. Sigilo de dados: o Direito à privacidade e os limites à função fiscalizadora do Estado. 2006. Disponível em <http://www.terciosampaioferrazjr.com.br/?q=/publicacoescientificas/49> Acesso em: 5 ago.2012.

FISCHER, Gustavo Daudt. As trajetórias e características do YouTube e Globo Media Center/ Globo Vídeos: Um olhar comunicacional sobre as lógicas operativas de websites de vídeos para compreender a constituição do caráter midiático da web. 2008. Tese (Doutorado em Ciências da Comunicação) Programa de Pós Graduação em Ciências da Comunicação, Universidade do Vale do Rio dos Sinos, São Leopoldo, RS, 2008, p.39.

LEITE, Marco Aurélio Souza. Internet e proteção legal à privacidade. Disponível em: http://www.webartigos.com/artigos/direito-de-privacidade-e-internet/18959/\#ixzz1zwbuUPJF. Acesso em: 5 jul.2012. 
MACHADO, Joicemegue Ribeiro; TIJIBOY, Ana Vilma. Redes Sociais Virtuais: um espaço para efetivação da aprendizagem cooperativa. Disponível em:

<http://www.inf.ufes.br/ cvnascimento/artigos/a37_redessociaisvirtuais.pdf>. Acesso em: 20 jul.2012.

MARQUES, Andréa Neves Gonzaga Marques Disponível em: <http://direito-legal.jusbrasil.com.br/ noticias/2166798/direito-a-honra>. Acesso em: 1 jul. 2012.

MARTINS, Flávio Alves. Utilização indevida de informações prestadas nas relações comerciais por meio da internet. Disponível em: http://sisnet.aduaneiras.com.br/lex/doutrinas/arquivos/051007.pdf. Acesso em: 20 ago. 2012.

MEIRA, Laís Moreschi; SOARES, Matheus Fernandes de Souza; PIRES, Panmella Rodrigues. Direito à privacidade e as relações na internet. Disponível em:

http://www.jurisway.org.br/v2/dhall.asp?id_dh=7319. Acesso em: 31 ago.2012.

MIRAGEM, Bruno. Responsabilidade por danos na sociedade de informação e proteção do consumidor: desafios atuais da regulação jurídica da Internet. Revista de Direito do Consumidor: RDC, Sao Paulo, ano 18, n. 70, p. 49, abr.-jun. 2009.

MORAES. Paulo Francisco Cardoso de. A vedação constitucional do anonimato aplicada à internet. 0 papel do estado brasileiro nna identificação dos usuários e responsabilização dos provedores. Disponível em : <http://www.ambito-

juridico.com.br/site/index.php?n_link=revista_artigos_leitura\&tartigo_id=9964\&revista_caderno=17>. Acesso em: 31 ago.2012.

NETO, Antonio Rulli; AZEVEDO, Renato A. Responsabilidade civil de provedores da internet: novos paradigmas. Disponível em: <http://por-leitores.jusbrasil.com.br/noticias/3161392/responsabilidadecivilde-provedores-da-internet-novos-paradigmas > Acesso em 31 ago.2012.

NIGRI, Deborah Fisch. Doutrina Jurídica brasileira: Crimes e Segurança na Internet. Caixias do Sul: Plenum, 2001.

SCAPIM, Eric. Direitos da personalidade: direito à imagem. Disponível em:

<http://www.viannajr.edu.br/site/menu/publicacoes/publicacao_direito/pdf/edicao2/Art02200511.pdf > Acesso em: 1 jul.2012.

VASCONCELOS, Fernando Antonio. Internet: Responsabilidade do provedor pelos danos praticados.Curitiba: Juruá, 2006.

VENOSA, Silvio de Salvo. Direito Civil: Parte geral. 5.ed. São Paulo: Atlas, 2005.

WOLTON, D. Internet, e depois? Porto Alegre: Sulina, 2003.

ZAGO, Gabriela da Silva. A possibilidade de responsabilização civil de terceiros por comentários a internet. Disponível em: <http://www.usp.br/anagrama/Zago_responsabilizacaocivil.pdf>Acesso em: 3 jul.2012.

Recebido em: 15.08.2012 / Aprovado em: 04.09.2012 